\title{
PRÁTICAS ESTRATÉGICAS DE ORÇAMENTAÇÃo E FATURAMENTO NA ADMINISTRAÇÃo PÚBLICA: UM ESTUDO DE CASO NA MARINHA DO BRASIL \\ RESUMO
}

Nas organizações públicas da administração direta no Brasil, a disponibilidade de recursos financeiros é baseada nos recursos orçamentários anuais; o processo para uso é definido em legislação e pode ser moroso; e os recursos financeiros não utilizados em um exercício social não são alocados ao exercício subsequente, prejudicando o planejamento e a ação de longo prazo. Esse contexto de restrições à ação torna-se particularmente complexo para organizações que atuam na área de Ciência, Tecnologia \& Inovação, como o Centro de Análises de Sistemas Navais - CASNAV, que pertence à Marinha do Brasil e desenvolve projetos de duração continuada. O objetivo da pesquisa foi analisar como são formadas as práticas estratégicas de orçamentação e faturamento do CASNAV, de forma a lidar com as restrições e regras da administração pública, segundo a percepção dos praticantes envolvidos. O estudo baseou-se na perspectiva de estratégia como prática social, com foco no modelo de Whittington (2006). Foi realizado um estudo de caso único, de natureza descritiva, cujos dados foram mediante entrevistas, observação e análise de documentos e tratados pela técnica de análise de conteúdo. Dentre os principais resultados, destacase que: (a) formação das práticas estratégicas está diretamente ligada ao processo de interação com os clientes (b) flexibilidade para lidar com as restrições orçamentárias ou financeiras está em grande parte relacionada às necessidades dos clientes; e (c) prática de orçamentação e faturamento é viabilizada pela formalização das atribuições dos praticantes, pela proatividade e interação com clientes e pelas competências gerenciais desenvolvidas internamente.

Palavras chave: Contabilidade; Gestão Pública; Prática Estratégica; Orçamentação; Faturamento. Área temática: Controladoria e Contabilidade Gerencial

\footnotetext{
${ }^{1}$ Universidade Federal do Rio de Janeiro - UFRJ, Brasil

E-mail: dap0467@gmail.com

${ }^{2}$ Universidade Federal do Rio de Janeiro - UFRJ, Brasil

E-mail: fernanda.sauerbronn@ facc.ufrj.br

${ }^{3}$ Universidade Federal do Rio de Janeiro - UFRJ, Brasil

E-mail: anafonseca@facc.ufrj.br

${ }^{4}$ Universidade Federal do Rio de Janeiro - UFRJ, Brasil

E-mail: malvaro@facc.ufrj.br
}

Denise de Almeida Pereira ${ }^{1}$ Fernanda Filgueiras Sauerbronn ${ }^{2}$ Ana Carolina Pimentel Duarte da Fonseca ${ }^{3}$ Marcelo Alvaro da Silva Macedo ${ }^{4}$ 


\section{STRATEGIC PRACTICES OF BUDGETING AND BILLING IN PUBLIC ADMINISTRATION: A CASE STUDY IN THE BRAZILIAN NAVY}

\section{ABSTRACT}

In the public institutions of Brazilian direct administration the availability of financial resources is based on yearly budget funds; the process for use of resources is set in legislation and can be time consuming; and unused funds in one fiscal year can not be allocated to the following year. This context of constraints to action becomes particularly complex for organizations that act in the area of Science, Technology \& Innovation, like Centro de Análises de Sistemas Navais - CASNAV, that belongs to the Brazilian Navy. Thus, the objective of the research was to analyze how CASNAV's strategic practices of budgeting and billing are formed, in order to deal with the restrictions and rules of public administration, according to the perception of practitioners involved in the process. This study was based on the perspective of strategy as a social practice and focused on the model of Whittington (2006). The single case study had a descriptive nature, which data collection was done through interviews, observation and analysis of documents and then treated by content analysis technique. Among the main results of the analysis highlights that: a) formation of strategic practices is directly linked to the process of interaction with customers; b) flexibility to deal with the financial or budgetary constraints is largely related to the client's needs; and (c) budgeting and billing practice is made possible by formalization of practitioners' attributions, the proactivity and interaction with customers and the managerial skills developed internally.

Keywords: Accounting; Public Management, Strategic Practices, Budgeting and Billing. Thematic Area: Controlling and Management Accounting 


\section{INTRODUÇÃO}

Nas organizações públicas da administração direta, a disponibilidade de recursos financeiros é baseada nos recursos orçamentários a elas destinados anualmente. Nelas, o processo para utilização dos recursos (execução da despesa) é definido em legislação e pode ser moroso e os recursos financeiros não utilizados em um exercício social não são alocados ao exercício subsequente, prejudicando o planejamento de logo prazo. Isso não é diferente na Marinha do Brasil (MB), pois, para que possa exercer, de forma mais eficiente, a defesa e a fiscalização marítima, a organização recebe recursos do governo federal e submete-se aos requisitos legais relacionados a orçamento e execução financeira. Simultaneamente, outro grande desafio advém da adoção do enfoque gerencial no Plano Plurianual (PPA) 2012-2015, cujo modelo de gestão por resultados encerra valores de eficiência e controle de resultados por iniciativa (Cavalcante, 2012).

Esses desafios vão de encontro aos usuais cortes orçamentários, que geram as restrições financeiras anuais, impactando diretamente a execução das metas estabelecidas. Além disso, cabe destacar as restrições da cultura burocrática ainda observada na Administração Pública (Motta, 2013). Diante de um contexto de hibridismo entre os modelos burocrático e gerencial (ver Valadares \& Emmendoerfer, 2012; Drummond, Silveira \& Silva, 2014), lidar com essas restrições legais e orçamentárias torna-se um desafio para organizações da administração pública que desenvolvem projetos de ciência, tecnologia e inovação. Para essas organizações, é necessário lidar com as restrições impostas pelas regras e regulamentos relacionados aos processos de orçamentação e faturamento e, ao mesmo tempo, com o aparato burocrático e normatizador aos quais os administradores públicos estão sujeitos. Essas são questões tidas como incompatíveis com uma organização que atua na área de inovação tecnológica que é caracterizada na literatura como sendo dotada de flexibilidade, de maior autonomia dos empregados e pela ausência de regras rígidas de trabalho. Para essas organizações, a mudança - não a estabilidade - é a ordem natural, de forma a facilitar a inovação, assim como a eficiência (Matias-Pereira \& Kruglianskas, 2005).

Diante desse contexto, o presente estudo colocou foco sobre uma Organização Militar Prestadora de Serviços (OMPS) na área de Ciência, Tecnologia \& Inovação (CT\&I) e pertencente à estrutura organizacional da MB. Foi selecionado o
Centro de Análises de Sistemas Navais - CASNAV, uma organização que, para alcançar seus objetivos estratégicos, desenvolve projetos de duração continuada e plurianuais. $\mathrm{O}$ processo de orçamentação e faturamento de projetos do CASNAV mostra-se como objeto de estudo relevante, face às restrições orçamentárias dadas pelas condições de adaptação às reduções ou às ampliações de recursos financeiros ao longo de cada exercício social.

Conforme sugerido por Bryson, Berry e Yang (2010), é necessário compreender mais atentamente a natureza das práticas de gestão estratégica na administração pública para atender aos desafios necessários a um melhor desempenho de longo prazo.

Portanto, o estudo busca responder à seguinte pergunta de pesquisa: Como são formadas as práticas de orçamentação e faturamento do CASNAV, de forma a lidar com as restrições e regras da Administração Pública, segundo a percepção dos praticantes envolvidos no processo? Ao responder à pergunta formulada busca-se compreender como os praticantes formam práticas estratégicas no processo de orçamentação e faturamento no CASNAV, de forma a cumprir a missão da organização e a atender às demandas da sociedade, em um contexto de hibridismo entre os modelos burocrático e gerencial.

Para tal, este artigo está estruturado em cinco seções: esta primeira, introdutória; a segunda apresenta a revisão de literatura; a terceira desenvolve a metodologia do trabalho; na quarta, há a análise dos dados e dos resultados; a quinta são traçadas considerações finais e apresentadas implicações para as práticas estratégicas na administração pública.

\section{REVISÃO DA LITERATURA}

\subsection{Modelos de gestão na administração pública e práticas correspondentes}

O avanço de uma agenda de Reforma do Estado no mundo foi impulsionado pelo argumento da crise do Estado, devido ao endividamento público, e pelas deficiências na capacidade de atendimento às demandas dos cidadãos (Lynn, 2005). Governos começaram a buscar alternativas de gestão baseados na incorporação de modelos dominantes da gestão empresarial, principalmente com foco na gestão estratégica de organizações (Bresser-Pereira, 2000). Consequentemente, alguns autores de administração pública, argumentaram favoravelmente à adaptação de modelos gerenciais privados para o âmbito público (Ferlie, 2002), enquanto outros reconheciam a 
Práticas Estratégicas de Orçamentação e Faturamento na Administração Pública: Um Estudo de Caso na Marinha do Brasil

existência de entraves na adaptação a contextos específicos (Mintzberg, 1996).

Dentro desse cenário, resgata-se um debate que reconhece a vinculação das transformações na gestão de organizações, privadas e públicas, às mudanças advindas (a priori ou a posteriori) das teorias organizacionais (Prestes Motta \& Vasconcelos, 2004). Consequentemente, as transformações nos modelos e práticas de gestão acompanham (e ajudam a moldar) as modas e manias que informam a adoção de modelos de gestão em organizações (Whittington, 2004: 65). Informam também as expectativas que se tem, por exemplo, em relação aos indivíduos ou aos gestores (de topo ou de nível médio) no que se refere à adaptação e formação das práticas de gestão nas organizações (Mantere, 2008).

A presente pesquisa posiciona-se fundamentalmente à luz das transformações nos modelos de administração pública e, subjacentes ao mesmos, os pressupostos teóricos a cerca da natureza humana e das organizações (Andion, 2012). Reconhece-se que a transição entre diferentes correntes teóricas estão relacionadas à implantação de um modelo gerencial na administração pública no Brasil e um consequente hibridismo (Pinho, 1998) e suas consequências para o planejamento e a gestão estratégica no setor público (Poister, 2010).

Segundo a literatura de administração pública (AP), existem tradicionalmente três formas de administrar o Estado: a "administração patrimonialista", a "administração pública burocrática" e a "administração pública gerencial" (Paula, 2005). A administração patrimonialista é do Estado, mas não é pública, na medida em que não visa ao interesse público. É a administração típica dos Estados que antecederam o capitalismo industrial, mais particularmente das monarquias absolutas que antecederam imediatamente o capitalismo e a democracia (Medeiros, 2006). Contemporaneamente, releva-se nas práticas em que se confunde o patrimônio privado com o patrimônio público, sobrevive através do clientelismo, do nepotismo e da corrupção (Pinho, 1998). Na teoria política de Max Weber, o patrimonialismo é um modo de exercício legítimo de poder político, ancorado no tipo de "dominação tradicional". A partir da análise do fundamento da legitimidade de dar ordens e da respectiva obediência pelos súditos, Weber intenta descobrir como se procede ao fenômeno da dominação no seio das relações sociais (Rocha Neto, 2008).

A administração pública burocrática é aquela baseada em um serviço civil profissional, na dominação racional-legal weberiana e no universalismo de procedimentos, expresso em normas rígidas de procedimento administrativo (Secchi, 2009). O modelo burocrático enfatiza aspectos formais, controlando processos de decisão, estabelecendo uma hierarquia funcional rígida, baseada em princípios de profissionalização e formalismo. Os procedimentos formais são feitos por funcionários especializados, com competências fixas, sujeitos ao controle hierárquico (Motta, 2013). Há a profissionalização do funcionário burocrático, que exerce o cargo técnico em razão de sua competência, comprovada por processo de seleção (Andrews \& Bariani, 2010). Cabe ressaltar que, em 1936, com o objetivo de realizar a modernização administrativa, foi criado no Brasil o Departamento Administrativo do Serviço Público (DASP), onde foi instituída a função orçamentária, enquanto atividade formal e permanentemente vinculada ao planejamento racional e centralizado (Andrews \& Bariani, 2010). Entretanto, conforme aponta Pinho (1998: 61-62), a reforma iniciada na década de 30 instalou "algo parecido", ou quase-weberiano, pois dela não nasceu uma administração pública moderna, ágil, eficiente e eficaz que fizesse frente à uma "sólida estrutura patrimonialista".

Entre a década de 30 e meados dos anos 90, as iniciativas realizadas no Brasil visando a transformação da administração pública brasileira foram pouco exitosas e nem sequer se assemelharam a reformas em si, como se fossem "novos rótulos em velhas garrafas" (Pinho, 1998: 68).

Este cenário modificou-se apenas com a propostas da administração pública gerencial, também chamada de "Nova Gestão Pública" (New Public Management), que foi introduzida no Brasil a partir de meados da década de 90 (MARE, 1995). Com a proposta de passagem para um modelo pós-burocrático, a expectativa relacionada à Administração Gerencial envolve um Estado não mais produtor de bens e serviços, mas regulador da economia e da sociedade, tanto no aspecto econômico como de outras questões sociais relevantes, como o meio ambiente (Medeiros, 2006). O enfoque muda, passando para o controle de resultados pretendidos, atenuando os rígidos controles procedimentais do período antecedente. O alicerce desse terceiro modelo de Administração Pública é o princípio da eficiência, o qual foi inserido no caput da Constituição Federal por meio da Emenda Constitucional $n^{\circ}$. 19, de 1998.

Segundo Bresser-Pereira (2000), a Administração Pública gerencial deve deslocar a ênfase dos procedimentos - meios, para os resultados - fins, como uma foram de defender a coisa pública. Ao enfatizar resultados, contrapõe-se à ideologia do formalismo e do rigor técnico da burocracia tradicional (Hood, 2005). Pretende-se reforçar a governança - a capacidade de governo do Estado - através da transição programada de um tipo de administração pública burocrática, rígida e ineficiente, voltada para si própria e para o controle interno, para uma administração pública gerencial, flexível e eficiente, voltada para o atendimento do cidadão (Secchi, 2009). 
Práticas Estratégicas de Orçamentação e Faturamento na Administração Pública: Um Estudo de Caso na Marinha do Brasil

Nesse modelo, as organizações da administração pública gerencial deveriam ver o cidadão como contribuinte de impostos e como cliente dos seus serviços (Hood, 2005). Assim, os resultados da ação do Estado devem ser considerados bons não porque os processos administrativos estão sob controle e são seguros, como quer a administração pública burocrática, mas porque as necessidades do cidadãocliente estão sendo atendidas (Ferlie, 2002). Portanto, tornam-se fundamentais: a definição clara de objetivos para cada unidade da administração; a descentralização e a mudança de estruturas organizacionais; mudanças culturais com a adoção de valores e de comportamentos gerenciais; a busca por qualidade nos serviços e pela excelência em gestão (Bresser-Pereira, 2000: 13).

Desde os anos 1980, as administrações públicas em todo o mundo realizaram mudanças substanciais nas políticas de gestão pública e no desenho de organizações programáticas (Lynn, 2005). Essas reformas administrativas consolidam novos discursos e práticas derivadas do setor privado e os usam como benchmarks para organizações públicas em todas as esferas de governo (Ferlie, 2002).

\subsection{Um breve histórico sobre planejamento, execução e controle}

A fim de investigar como são formadas as práticas de orçamentação e faturamento na administração pública, é necessário traçar um breve histórico necessário ao entendimento das normas e regras que informam sobre o processo de planejamento, execução e controle, mais especificamente as normatizações sobre Orçamento Público.

A Administração Pública é, frequentemente, considerada como uma estrutura hierarquizada com diferentes níveis de autoridade e sua organização circunscreve-se ao Poder Executivo. Segundo Motta (2001: 182), dentre os atos administrativos, o principal é a Lei Orçamentária, em função de ser a responsável por quase todas as alterações patrimoniais. Portanto, a principal fonte de formação do Patrimônio de um órgão público é o orçamento público. Motta (2001: 182) cita ainda que muito do entendimento da escrituração dependerá do conhecimento do conteúdo do próprio orçamento e da execução do mesmo.

A partir de uma análise das normas gerais das finanças públicas e dos orçamentos atualmente em vigor, pode-se concluir que de acordo com a Constituição Federal (CF) e a Lei de Responsabilidade Fiscal (LRF), os instrumentos de planejamento devem guardar perfeita integração entre si (Nascimento, 2010). Fazendo um comparativo entre os instrumentos, podemos dizer que o PPA estabelece os programas que constarão da Lei Orçamentária Anual (LOA); a Lei de Diretrizes Orçamentárias (LDO) dispõe sobre as diretrizes para a elaboração da LOA; e a LOA viabiliza a realização anual dos programas.

Cabe também destacar que ao longo dos últimos anos, especialmente após o ano 2000, o Governo Federal vem introduzindo modificações em seu sistema de planejamento, atribuindo ênfase à gestão por resultados em detrimento ao gerenciamento funcional, por áreas de atuação, largamente empregado em períodos passados (Cardoso Jr., 2015: 144-145). Tal mudança de perspectiva apenas reforçou a importância do PPA, introduzido no Sistema de Planejamento e Orçamento Federal pela Constituição Federal de 1988, como instrumento de planejamento do Governo Federal. Todo o processo de mudança foi baseado na adoção de práticas simplificadoras e descentralizadoras, pautadas, sobretudo, na ligação entre o planejamento e o orçamento (Cardoso Jr., 2015).

Na MB, até 1963 , o orçamento compreendia apenas a previsão das receitas e a fixação das despesas para determinado período, tratando-se de uma mera peça contábil financeira. Nesse ano, com a criação do Plano Diretor (PD), passou a contar com um instrumento de planejamento, execução e controle, de caráter permanente, inerente às gestões orçamentária e financeira, desenvolvidas nos diversos escalões administrativos, visando à adequação dos recursos disponíveis às necessidades da MB (Marinha do Brasil, 2008). A partir de então, passou a dispor de informações orçamentárias e financeiras a respeito de áreas específicas de atuação, permitindo adequar os créditos, tradicionalmente escassos, às necessidades planejadas. O planejamento e a execução foram otimizados, contribuindo para a continuidade administrativa. Seu funcionamento é realizado por meio de um sistema denominado Sistema do Plano Diretor (SPD), que se constitui em um conjunto de conceitos, processos, regras de funcionamento, atores e procedimentos, os quais permitem o planejamento, a execução e o acompanhamento das atividades orçamentárias, bem como a produção de informações gerenciais necessárias à tomada de decisão (Marinha do Brasil, 2013).

Enquanto o PD remonta a um instrumento permanente de gestão orçamentária e financeira, o SPD trata de sua projeção sobre a estrutura administrativa da MB. Seus Órgãos e Organizações Militares são interdependentes, cuja interação é pautada por procedimentos específicos, os quais objetivam alcançar os propósitos para os quais foi criado (Brasil, 2010).

Com relação à gestão por resultados na $\mathrm{MB}$, em 1994, a Alta Administração Naval optou pela mudança na forma de gestão de suas organizações industriais e prestadoras de serviços, criando as Organizações Militares Prestadoras de Serviços (OMPS) e o Sistema OMPS, visando o aprimoramento dos controles internos e a determinação mais eficiente dos custos das 
Práticas Estratégicas de Orçamentação e Faturamento na Administração Pública: Um Estudo de Caso na Marinha do Brasil

organizações militares industriais e prestadoras de serviços (Marinha do Brasil, 2008: 1). Para operacionalizar a implantação do sistema, foram utilizadas duas ferramentas: o Sistema Integrado de Administração Financeira do Governo Federal (SIAFI) e a Contabilidade de Custos. Assim, conceitualmente, OMPS é a organização militar que presta serviços a outras organizações militares e, eventualmente, a organizações extra-Marinha. Vale ressaltar que uma OMPS não visa lucro, pois isso oneraria a própria Marinha, que é o seu principal "cliente", devendo, portanto, faturar o necessário para cobrir os seus gastos, de acordo com o preconizado nas normas internas da Marinha. Porém, otimizar o emprego dos recursos humanos, materiais e tecnológicos de uma OMPS deve ser uma constante preocupação, em especial de seu dirigente. Para tal, é necessário a OMPS possuir um processo de gestão estruturado, que incorpore as diversas fases desde o planejamento estratégico, passando pelo planejamento operacional, até chegar à fase de execução e controle de suas atividades (Brasil, 2010). Portanto, o Sistema OMPS deve ser encarado como um Sistema Gerencial, que engloba todos os setores da MB e não apenas um Sistema de Custos relacionado tão somente a aspectos contábeis e financeiros (Santos, Fonseca e Sauerbronn, 2014).

Recentemente, a Administração Naval consolidou seus entendimentos acerca das características, diversidade e importância dos indicadores de desempenho para a gestão administrativa eficiente de suas OMPS. De acordo com a norma da Secretaria Geral da Marinha (SGM-304), as organizações medem seus desempenhos para: a) avaliar o atendimento aos requisitos dos clientes/usuários; b) avaliar o atendimento aos requisitos da organização; e c) ter um instrumento efetivo de gerenciamento, a fim de identificar deficiências e oportunidades de melhorias. Dessa forma, a OMPS consolida mensalmente suas informações sobre custos, despesas e faturamento em relatórios, que são enviados à Diretoria de Finanças da Marinha, a qual tem por atribuição realizar a análise gerencial das OMPS, bem como acompanhar o desempenho econômicofinanceiro delas e prover a Alta Administração Naval de elementos sobre tal desempenho nas avaliações trimestrais do Conselho Financeiro da Marinha (Marinha do Brasil, 2008).

Vale destacar que a Lei $n^{\circ}$ 9.724/98 consolidou os procedimentos até então instituídos, estabelecendo que os objetivos, as metas e os indicadores de desempenho das OMPS seriam regidos por um "Contrato de Autonomia de Gestão" e que o Decreto n ${ }^{\circ}$ 3.011/99 estabeleceu que as OMPS poderiam se qualificar para Assinatura do Contrato de Autonomia de Gestão, bem como os mecanismos para tal. Dessa forma, as OMPS qualificadas teriam autonomia gerencial, financeira e orçamentária com uma redução formal da burocracia. Assim, em 2001, o CASNAV assinou seu primeiro Contrato de Autonomia de Gestão e, em função desse contrato, dispõe de maior flexibilidade na gestão dos recursos, estipulando metas, resultados a alcançar e métodos de avaliação de desempenho. Desde então, vem assinando aditivos ao referido contrato e o Termo Aditivo ao Contrato de Autonomia de Gestão vigente tem como anexo o Plano Estratégico da organização (CASNAV, 2012; 2012a).

O presente estudo situa-se diante desse cenário de crescente busca por autonomia e flexibilidade, por meio do sistema OMPS, e que ao mesmo tempo submete-se aos requisitos institucionais legais relacionados a orçamento e execução financeira, bem como a noções hierarquizantes de uma organização militar. Para tal, considera-se oportuno colocar o foco sobre as práticas de orçamentação e faturamento dado seu potencial para revelar como estas são recursivamente desenvolvidas e adaptadas por seus praticantes cotidianamente.

\subsection{Investigando prática social e praticantes}

Vale considerar que cada um dos modelos de gestão na AP parte de certos pressupostos a respeito da natureza humana; ou seja, cada modelo reconhece de forma distinta os indivíduos que atuam nas organizações públicas (Guerreiro Ramos, 1981), apresentando características do 'homem econômico' e do 'homem organizacional' (Prestes Motta \& Vasconcelos, 2004: 26-28 e 148). Entretanto, mostra-se fundamental para este estudo reconhecer quem são e como agem os indivíduos nas organizações públicas, para compreender como as práticas estratégicas cotidianas são influenciadas por cada um desses modelos (como moldam, quem são e o que fazem esses indivíduos) e, por outro lado, como essas práticas são viabilizadas, ou não, por ambos.

Como sugerido por Cuganesan, Dunford e Palmer (2012), o estudo de práticas específicas de contabilidade gerencial em organizações públicas pode ser útil para contrabalancear a ênfase sobre o setor privado nas pesquisas que utilizam a perspectiva de estratégia como prática social.

O presente estudo vincula-se à perspectiva da prática social na área de administração e ciências contábeis (ver Walter, Augusto \& Fonseca, 2011; Lounsbury, 2008). Nesta abordagem tende-se a compreender as organizações como fenômenos sociais, sujeitos às questões de estabilidade e de mudança, nas quais devem ser conciliadas as preocupações relacionadas tanto com microprocessos organizacionais quanto com o ambiente institucional. Logo, vincula-se à uma perspectiva epistemológica que considera a contabilidade como ciência social aplicada e, portanto, que reconhece a importância de um retorno às teorias 
Práticas Estratégicas de Orçamentação e Faturamento na Administração Pública: Um Estudo de Caso na Marinha do Brasil

sociológicas, mais especificamente aquelas já utilizadas por pesquisadores de sociologia organizacional, que reconhecem a importância da prática social (ver Ryan, Scapens \& Theobald, 2002; Baxter \& Chua, 2003).

Nessa perspectiva, o pesquisador em contabilidade deve considerar que ações humanas são resultantes de influências externas, são intencionais e reflexivas e ocorrem dentro de uma estrutura de regras, por isso ele não pode apenas medir determinada situação, mas deve compreender o processo para não tirar as ações do seu contexto (Smith, 2011, p. 4). Ryan et al. (2002) destacam que um estudo dessa natureza explora como a contabilidade é condicionada pelo sistema socioeconômico, como tal sistema fornece regras que estruturam certos tipos de comportamentos organizacionais e como as regras emergem das práticas dos participantes da organização. Os autores destacam que pesquisas contábeis interpretativas buscam entender o mundo social e, ainda que possam construir teorias para oferecer compreensão da estrutura social, não fornecem teorias preditivas. Tais pesquisas ao localizar as práticas correntes de contabilidade em seus contextos históricos, econômicos, sociais e organizacionais permitem o entendimento da contabilidade gerencial como prática social.

Como indicado por Ryan et al (2002), a realidade emerge de uma subjetividade criada e é objetivada pela interação humana intencional. Assim, a contextualização da contabilidade gerencial evidencia mudança social objetiva por meio da ação de indivíduos ou grupos que impulsionam mudanças por rearranjos espaciais e desenvolvimentos conceituais, sendo que as práticas de contabilidade gerencial são partes de ações concretas intencionais.

O presente estudo inspira-se na teoria institucional por ser uma abordagem sociológica que tem sido aplicada na área contábil para explicar processos de formação de práticas (Guarido Filho; Costa, 2012). Essa teoria, refutando as premissas da teoria neoclássica que têm orientado a abordagem normativa da Contabilidade Gerencial, foca-a como uma instituição dentro da empresa, isto é, uma rotina formada por hábitos que dá sentido a determinado grupo de pessoas, sendo esta rotina amplamente aceita de forma inquestionável.

O ponto central sobre o qual repousa a teoria institucional é a ideia de hábitos de um grupo de pessoas: a instituição é estruturada a partir de rotinas e as rotinas dependem de hábitos. Os hábitos caracterizam-se como uma tendência para se engajar em formas de ação anteriormente adotadas. Formalizados e institucionalizados, os hábitos formam as rotinas que, por sua vez, moldam as instituições (Guerreiro, Frezatti \& Casado, 2006, p.8).

Da mesma forma, a teoria institucional, é uma perspectiva que não vê o comportamento coletivo apenas como um agregado de ações individuais. Sob essa abordagem o comportamento coletivo é explicado por regras socialmente geradas, "há um ambiente técnico e vários ambientes institucionalizados”, assim, as práticas de contabilidade gerencial são influenciadas pela complexidade dos múltiplos ambientes institucionalizados na organização (Baxter \& Chua, 2003, p. 98).

Dentro da estratégia como prática coexistem os atributos da recursividade e adaptação, que buscam atender respectivamente às necessidades de estabilidade e mudança com que se deparam os estrategistas. A recursividade é ilustrada pelas rotinas organizacionais socialmente construídas enquanto que a adaptação resulta da interação do macro contexto (sociedade) com o micro contexto (organização) (Jarzabkowski, 2004).

O estudo sobre a formação de práticas estratégicas em organizações é situado diante da teoria institucional, entretanto, no presente estudo o principal foco encontra-se no modelo de análise apresentado por Whittington (2006). Do modelo destaca-se o papel dos praticantes na formação das práticas que são também informadas por regras, normas e recursos implicados simultaneamente no processo em que se desenrolam. $\mathrm{O}$ modelo de Whittington (2006) relaciona prática, práxis e praticantes e indica a influência de atores externos na adoção de práticas estratégicas nas organizações.

Segundo o autor, a concepção de prática recorre a rotinas compartilhadas de comportamento, incluindo tradições, normas, maneiras de pensar e atitudes em um sentido mais amplo, ou seja, prática é alguma coisa que guia a ação estratégica. Já a práxis consiste na própria atividade, em uma atividade atual que os atores executam em prática, consistindo no trabalho intraorganizacional exigido para fazer e executar a estratégia. Praticantes são os atores da estratégia, são os estrategistas que executam as atividades de prática, ou seja, realizam atividades envolvidas com a formulação e a implementação da estratégia. As práticas estratégicas são utilizadas pelos praticantes em sua práxis (Whittington, 2006). Esse modelo destaca praticantes internos e externos à organização. Os internos compartilham algumas práticas e confiam nelas; no entanto, em algum momento, eles podem alterar uma prática, realizando uma adaptação. Eles podem, também, incorporar uma prática nova trazida para a organização por um praticante extraorganizacional. Assim, os praticantes se configuram como centrais na transferência e na inovação de práticas estratégicas. A práxis intraorganizacional é marcada por práticas extraorganizacionais; as práticas bem-sucedidas são realizadas por praticantes influentes e a práxis forma os praticantes (Whittington, 2006).

Inspirado no modelo por Whittington (2006), considera-se no estudo que outra organização (por 
Práticas Estratégicas de Orçamentação e Faturamento na Administração Pública: Um Estudo de Caso na Marinha do Brasil

exemplo, outro órgão da Administração Pública) pode atuar como praticante externo à organização, ao interferir na adoção de uma nova prática estratégica pela organização e, até, propiciar essa adoção. Isso pode ser um indício da ocorrência de um mecanismo isomórfico.

Segundo Walter e Augusto (2011) a principal contribuição do modelo de Whittington (2006) é explicar de onde surgem as práticas, isto é, que as práticas dos praticantes $\mathrm{A}, \mathrm{B}$ e C são oriundas de um conjunto de práticas que a organização proporciona a seus praticantes (ver figura 1). Em contraposição, o praticante $\mathrm{D}$ é extraorganizacional e introduz novas práticas na organização, ou seja, práticas ainda não legítimas entre seus praticantes internos. Contudo, os autores citam que Whittington (2006) explora apenas como as práticas extraorganizacionais são inseridas nas organizações por meio de estrategistas externos, desconsiderando que os estrategistas internos também adotam práticas estratégicas oriundas do campo organizacional por meio de outros mecanismos alheios à atuação de atores externos.

É importante destacar nessa perspectiva que as pessoas não se adaptam passivamente às circunstâncias que encontram, eles usam essas circunstâncias criativamente para o escopo de sua escolha, ao moldar e misturar regras e recursos (Clegg, Couparsson \& Phillips, 2006: 124). Para Mantere (2008), os gerentes de nível médio recebem autorização explícita dos gerentes de topo para realizar mudanças no trabalho cotidiano, por meio da alocação de recursos. Esta reflete as mudanças necessárias no trabalho cotidiano e é vista como condição viabilizadora das práticas. Portanto, os recursos alocativos implicam na distribuição institucionalizada de recursos materiais, tais como mercadorias, objetos, e propriedades, inclusive a forma pela qual os diferentes grupos acessam e desdobram aqueles recursos (Jarzabkowski, 2008).

O modelo de Whittington (2006) mostra-se interessante para estudos em contabilidade gerencial, pois permite colocar foco no levantamento das práticas cotidianas, práxis e praticantes, inclusive, permitindo identificar como atores externos facilitam ou restringem suas práxis, estabelecendo regras na execução de projetos de inovação e com atores internos, que em contrapartida viabilizam tal execução. Estas são dimensões importantes para o alcance do objetivo de analisar como são formadas as práticas cotidianas de forma a lidar com as restrições e regras da Administração Pública no desenvolvimento de projetos de inovação.

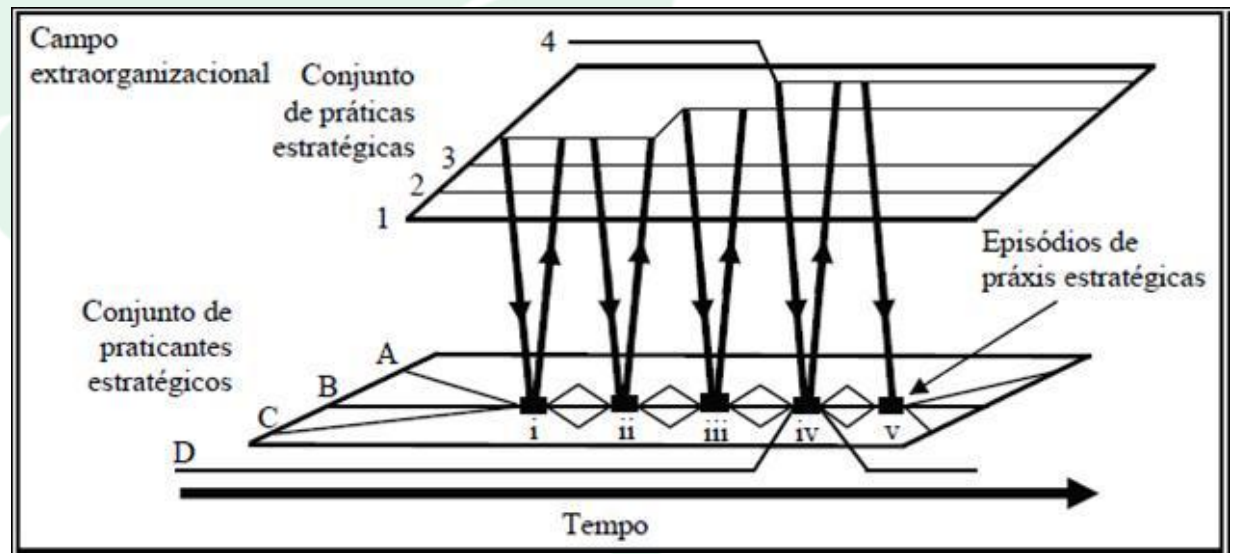

Figura 1 - Integração entre práxis, prática e praticantes Fonte: Whittington (2006).

Finalizando esta seção, buscou-se com a construção da moldura teórica ora apresentada, fundamentada no modelo de Whittington; nas normas e regras sobre Orçamento Público; e no processo orçamentário e na gestão por resultados da Marinha do Brasil, angariar subsídios como forma de consubstanciar as análises a serem empreendidas nas próximas seções. Dessa forma, a próxima seção apresentará os aspectos inerentes à metodologia utilizada e justificará a utilização do modelo escolhido para a investigação realizada pela pesquisa.

\section{MÉTODO}

A presente pesquisa possui uma natureza qualitativa e descritiva, pois procurou identificar as práticas cotidianas e como são adaptadas para atender às restrições/regras da Administração Pública. Segundo Vieira e Zouain (2007: 15) o método qualitativo é definido de acordo com o axioma de crenças do investigador e atribui importância fundamental à descrição detalhada dos fenômenos e dos elementos que o envolvem, aos depoimentos dos atores sociais 
Práticas Estratégicas de Orçamentação e Faturamento na Administração Pública: Um Estudo de Caso na Marinha do Brasil

envolvidos, aos discursos, aos significados e aos contextos.

Foi realizado um estudo de caso que, segundo Stake (2005: 86) é definido pelo interesse em casos específicos e não pelos métodos de investigação utilizados. Mas quanto mais o objeto de estudo é um exclusivo sistema específico, delimitado, maior será a utilidade do raciocínio epistemológico. Quanto mais o pesquisador tem interesse próprio no caso, mais o foco de estudo será na singularidade do caso, na particularidade do contexto, das questões e da história (Stake, 2005: 103). O pressuposto subjacente à presente pesquisa é de que os estudos de casos individuais podem produzir vários tipos de resultados, cada um dos quais deve ser valorizado por quem procura melhorar a resolução de problema coletivo através de atividades tais como política, gestão, produção e investigação profissional (Barzelay, 1993). Assim, a pesquisadora fez a opção de estudo de caso único.

A definição constitutiva das categorias de análise prática social, práxis, praticantes, rotina e normas e regras foi baseada nas definições conceituais de Whittington (2006); as categorias autonomia, flexibilização e recursos foram baseadas nas definições conceituais de Prestes Motta e Vasconcelos (2004), Poister (2010) e no Plano Diretor da Reforma do Aparelho do Estado (MARE, 1995). A definição operacional, refere-se a como a categoria será identificada, verificada ou medida na realidade, ou seja, representa a operacionalização da definição constitutiva e foi baseada na análise dos dados por parte da pesquisadora. As entrevistas foram orientadas por categorias pertinentes ao objetivo da pesquisa, em um roteiro semiestruturado, as quais foram definidas preliminarmente e não surgiram novas categorias durante as entrevistas ou em seu processo de análise. Logo, não foram incluídas novas categorias.

Quanto aos meios de investigação, em uma primeira etapa, foi desenvolvida uma pesquisa bibliográfica e documental, mais especificamente, em livros, artigos, teses, dissertações, legislações, documentos normativos e manuais. Em uma segunda etapa da pesquisa, a coleta dos dados foi feita mediante entrevista em profundidade e observação participante, pois a pesquisadora participa há 3 anos do processo de faturamento da organização (por fazer parte do quadro de servidores civis assemelhados a oficiais). Isso possibilitou uma maior liberdade para acessar, tanto dados primários, quanto dados secundários, bem como facilitou o contato da pesquisadora com os entrevistados.

Utilizando as estratégias propostas por Moreira e Caleffe (2008) para a seleção da amostra, a pesquisadora optou inicialmente por entrevistar os membros da Organização estudada, levando em conta a participação de cada um no processo de orçamentação e faturamento do CASNAV. Em um segundo momento, adotou a amostragem bola-de-neve ou em série uma vez que no decorrer das entrevistas, os depoimentos indicavam membros-chave que possuíam informações ricas sobre as percepções atinentes ao processo de orçamentação e faturamento da OMPS.

Desse modo, a amostra selecionada foi composta por 10 entrevistas semiestruturadas e apresenta-se distribuída entre os departamentos (de Administração, de Sistemas, de Apoio Tecnológico, Assessoria/Secretaria), pelos seguintes níveis hierárquicos: estratégico (4 Chefes de Departamento), tático (3 Encarregados de Divisão) e operacional (3 Encarregados de Seção e Gerente de Projeto). Os entrevistados assinaram protocolo de entrevista.

Conduzidas de forma individual, entre janeiro e abril de 2014, as entrevistas tiveram duração média aproximada de 30 minutos, perfazendo um total de 214 minutos de gravação. Após transcritas, as entrevistas impressas foram entregues a cada entrevistado que solicitaram pequenos ajustes, que não afetaram o conteúdo do trabalho, mas facilitaram o entendimento do texto "falado". As alterações foram feitas e os entrevistados rubricaram todas as páginas da entrevista transcrita.

Os dados obtidos foram tratados pela técnica de análise de conteúdo (Bardin, 1977). De forma a responder à questão norteadora da pesquisa, os resultados estão apresentados na próxima seção estruturados em função das categorias - práxis, praticantes, flexibilização, rotinas, normas e regras, autonomia, recursos e prática social - analisadas à luz dos pressupostos dos modelos de gestão da Administração Pública.

\subsection{Organização estudada}

A organização estudada, o CASNAV, foi criada em 1975, com a finalidade de desenvolver estudos para a configuração e a otimização de sistemas de interesse da $\mathrm{MB}$, bem como controlar a execução das atividades de Pesquisa Operacional em todos os seus escalões (CASNAV, 2012). Como uma das 8 Instituições Científicas Tecnológicas (ICT), na estrutura orgânica atual da Marinha, ele é subordinado à Secretaria de Ciência, Tecnologia e Inovação da Marinha (SecCTM), que é ligada ao Comando da Marinha, que se reporta diretamente ao Ministério da Defesa. Para o cumprimento de suas tarefas, o CASNAV está estruturado organizacionalmente em três níveis, conforme a seguir. O Nível Estratégico é composto pelo Diretor, Vice-Diretor, Departamentos, Assessorias e Conselhos Técnicos, o Nível Tático é composto pelos Encarregados de Divisão e o Nível Operacional é composto pelos Gerentes de Projeto ou Encarregados de Seção (CASNAV, 2012a).

A estratégia do CASNAV, dentro do enfoque de seu Planejamento Estratégico, pode ser assim definida: 
Práticas Estratégicas de Orçamentação e Faturamento na Administração Pública: Um Estudo de Caso na Marinha do Brasil

"dominar o conhecimento para atender às necessidades tecnológicas de desenvolvimento autóctone das Organizações Militares da Marinha do Brasil (MB), nas áreas de sua competência; elevar continuamente o nível de qualidade dos seus serviços e produtos; e buscar a excelência da gestão" (CASNAV, 2012, p. 29). Em função do estabelecido em seu Regulamento, o CASNAV orienta suas atividades primordialmente à prestação de serviços para as organizações militares da MB. Como a atuação é focada, principalmente, na melhoria de processos, é essencial o estabelecimento de relações de confiança e comprometimento com os clientes. Por isso, na maioria dos casos, os projetos são desenvolvidos em conjunto, com participação ativa de representantes dos clientes, a quem se considera parceiros. Cabendo destacar ainda que, além de contar com militares e servidores civis especializados nas áreas de sua competência, o CASNAV tem um contrato firmado com a empresa FEMAR, a qual fornece apoio técnico na área de desenvolvimento de software para toda a MB e que é contratada pela modalidade de dispensa de licitação (CASNAV, 2012a).

O CASNAV segue as normas internas da MB, a exemplo da SGM-304, por se enquadrar como OMPS (Marinha do Brasil, 2008). Adicionalmente, os procedimentos de planejamento, controle e gerenciamento de projetos no CASNAV são detalhados em Procedimento Operacional específico, o qual integra seu Sistema de Qualidade.

Com base na análise do Procedimento Operacional $\mathrm{n}^{\mathrm{o}}$ 007/2013, foram descritos os procedimentos diretamente relacionados ao seu processo de orçamentação e faturamento. Assim, a análise do processo de orçamentação e faturamento do CASNAV, ao confrontar os dados documentais àqueles oriundos das entrevistas, permite descrever como são formadas as práticas de orçamentação e faturamento do CASNAV, de forma a lidar com as restrições e regras da Administração Pública, num contexto de convivência entre os modelos burocrático e gerencial.

\section{ANÁLISE DOS DADOS E RESULTADOS}

Antes de descrever a formação das práticas de acordo com o modelo de Whittington, serão apresentados resultados obtidos por categorias de análise do estudo, segundo sua origem e descrição, e quanto ao hibridismo dos modelos gerencial e burocrático.

\subsection{Resultados à luz das categorias de análise a) Práxis}

As práxis de orçamentação e faturamento estão descritas no Procedimento de Planejamento, Controle e Gerenciamento de Projetos. Essas atividades têm interação com atividades regidas por procedimentos de outras Divisões do CASNAV, como a de Relacionamento com o Cliente, a de Contabilidade de Custos e Faturamento e a de Edição de Documentos. Em função desse contexto, a orçamentação de um projeto e a sua aprovação usualmente precedem à futura execução.

Entretanto, a visão de que as restrições orçamentárias afetam as práxis do processo de orçamentação e faturamento de projetos é comum entre os atores que participam do referido processo. Os praticantes adaptam suas práxis (ver quadro 1) às realidades/necessidades dos clientes, que por sua vez, adequam seus projetos aos recursos recebidos de forma a lidar com as mesmas.

Quadro 1: Categoria de Análise Práxis

\begin{tabular}{|c|c|c|c|}
\hline & Origem & Descrição & $\begin{array}{c}\text { Modelo } \\
\text { predominante }\end{array}$ \\
\hline \multirow[t]{2}{*}{ Práxis } & $\begin{array}{l}\text { De restrições } \\
\text { orçamentárias }\end{array}$ & $\begin{array}{l}\text { Concentração de recursos em metas em andamento } \\
\text { para conclusão de mesmas; utilização do capital de } \\
\text { giro inicial disponibilizado para as OMPS; } \\
\text { utilização de softwares livres e realocação de } \\
\text { funcionários entre projetos; e adaptaçôes no escopo } \\
\text { ou cronograma do projeto de forma a atender o } \\
\text { cliente. }\end{array}$ & \multirow{2}{*}{$\begin{array}{l}\text { Hibridismo entre os } \\
\text { modelos gerencial } \\
\text { (atendimento à } \\
\text { realidade/necessidades } \\
\text { do cliente) e o } \\
\text { burocrático } \\
\text { (adequação dos } \\
\text { projetos aos recursos } \\
\text { recebidos). }\end{array}$} \\
\hline & $\begin{array}{l}\text { De restrições } \\
\text { financeiras }\end{array}$ & $\begin{array}{l}\text { Afetam a liquidação e o pagamento de despesas; } \\
\text { afetam a atualização tecnológica da OM e a } \\
\text { realização de viagens pelos envolvidos em projetos; } \\
\text { afetam negativamente o resultado final da OMPS } \\
\text { por conta de descontos ao cliente ou de não cobrar } \\
\text { por serviços prestados; e podem gerar } \\
\text { desmobilização de equipes. }\end{array}$ & \\
\hline
\end{tabular}

Fonte: Elaborado pelos autores 
Práticas Estratégicas de Orçamentação e Faturamento na Administração Pública: Um Estudo de Caso na Marinha do Brasil

\section{b) Praticantes}

Considerou-se no estudo que os atores responsáveis pelas práxis que formam as práticas de orçamentação e faturamento do CASNAV podem ser internos ou externos à $\mathrm{OM}$.

Conforme apontado por Whittington (2006), os praticantes internos compartilham algumas práticas e confiam nelas; no entanto, em algum momento, eles podem alterar uma prática, realizando uma adaptação, como evidencia um relato de que a administração científica ou burocrática não é seguida à risca. Pode ocorrer a execução de algum procedimento antes de sua criação/adaptação, o que mostra a capacidade de ação do praticante (ver quadro 2), mesmo que depois siga a forma/formato do modelo burocrático ("o escrito") para atender seus ditames de padronização.

Quadro 2: Categoria de Análise Praticantes

\begin{tabular}{|c|c|c|c|}
\hline & Origem & Descrição & Modelo predominante \\
\hline \multirow{3}{*}{ Praticantes } & $\begin{array}{c}\text { Atores } \\
\text { internos }\end{array}$ & $\begin{array}{c}\text { Compartilham algumas práticas e confiam } \\
\text { nelas, mas podem adaptá-las. }\end{array}$ & $\begin{array}{c}\text { Hibridismo entre o modelo } \\
\text { gerencial (capacidade de } \\
\text { adaptação das práticas pelo } \\
\text { praticante) e o burocrático } \\
\text { (formato padronizado). }\end{array}$ \\
\hline
\end{tabular}

Fonte: Elaborado pelos autores

Os relatos indicam que os praticantes podem, inclusive, incorporar uma prática nova trazida para a organização por um praticante extraorganizacional, como outro órgão da Administração Pública. Este aspecto ressalta a transição de um modelo Estadocêntrico, conforme aponta Andion (2012) para a incorporação de outros atores na co-produção dos serviços gerados por organizações públicas.

\section{c) Flexibilização}

A categorias de análise flexibilização é definida no presente estudo, em termos conceituais, como sendo o afrouxamento ou a eliminação de leis e normas; ou seja, a capacidade de adaptação às circunstâncias, ao invés da rigidez na gestão, e que são identificadas por meio das práxis desenvolvidas pelos praticantes de forma a lidar com as restrições/regras da AP (Poister, 2010 ; MARE, 1995).

Quadro 3: Categoria de Análise Flexibilização

\begin{tabular}{|c|c|c|c|}
\hline \multirow{7}{*}{ Flexibilização } & Origem & Descrição & $\begin{array}{c}\text { Modelo } \\
\text { predominante }\end{array}$ \\
\cline { 2 - 3 } & Do cliente & De prazo e escopo. & \\
\cline { 2 - 3 } & Interna & $\begin{array}{c}\text { Ajustes dos interesses do cliente com os do } \\
\text { CASNAV; antecipação ou postergação de tarefas do } \\
\text { cronograma do projeto; e de escopo, orçamento e } \\
\text { cronograma do projeto. }\end{array}$ & \multirow{2}{*}{$\begin{array}{c}\text { Modelo } \\
\text { gerencial }\end{array}$} \\
\cline { 2 - 3 } & Plano de Metas & Na alocação de recursos. & \\
\cline { 2 - 3 } & Do fornecedor & $\begin{array}{c}\text { Preço estimado e escopo variável em cada contrato } \\
\text { e delimitado pela quantidade de tarefas a serem } \\
\text { executadas em vários projetos; remanejamento de } \\
\text { pessoal entre projetos e retenção de profissionais. }\end{array}$ & \\
\hline
\end{tabular}

Fonte: Elaborado pelos autores 
Com a passagem para o modelo de Administração Pública gerencial, a administração passa a buscar o alcance de metas com a eficiência necessária. Nesse contexto, as três partes envolvidas no processo de orçamentação e faturamento (cliente, CASNAV e fornecedor) procuram flexibilizar suas ações de forma a atingir o objetivo comum: a execução dos projetos, ou seja, a conclusão de metas estabelecidas. Nesse sentido, observa-se a congruência com o modelo gerencial (quadro 3).

\section{d) Rotina}

As rotinas, característica do modelo burocrático, estão presentes na organização estudada em todos os níveis da organização, sendo: atividades previstas no Procedimento Operacional no nível operacional; tarefas com periodicidade regular, rotineiras, mas não repetitivas no nível tático e tarefas bem organizadas e pré-definidas no nível estratégico (ver quadro 4).

Quadro 4: Categoria de Análise Rotina

\begin{tabular}{|c|c|c|c|}
\hline \multirow{7}{*}{ Rotina } & Origem & Descrição & $\begin{array}{c}\text { Modelo } \\
\text { predominante }\end{array}$ \\
\cline { 2 - 3 } & $\begin{array}{c}\text { Nível } \\
\text { operacional }\end{array}$ & $\begin{array}{c}\text { Atividades previstas no Procedimento Operacional } \\
\text { (P.O.), assim como não previstas. }\end{array}$ & \multirow{2}{*}{$\begin{array}{c}\text { Modelo } \\
\text { burocrático }\end{array}$} \\
\cline { 2 - 3 } & Nível tático & $\begin{array}{c}\text { Tarefas com periodicidade regular, rotineiras, mas não } \\
\text { repetitivas. }\end{array}$ & \\
\cline { 2 - 3 } & $\begin{array}{c}\text { Nível } \\
\text { estratégico }\end{array}$ & Tarefas bem organizadas e pré-definidas. & \\
\hline
\end{tabular}

Fonte: Elaborado pelos autores

\section{e) Normas e Regras}

Normas e regras foram definidas como representando convenções sociais sobre o contexto e se constituem como guias de orientação para a ação. Observou-se que o processo de orçamentação e faturamento de projetos é extremamente normatizado, característica do modelo burocrático. Cabe destacar que as normas também são seguidas pelo nível estratégico, além de as regras estarem definidas em Planos, Programas ou Orientações. Porém, ao incorporar o sistema de gestão da qualidade, a administração implantou ferramentas gerenciais como o Modelo MPS.BR (Melhoria de Processo de Software Brasileiro), que agregam melhores práticas de gestão, preconizadas no modelo gerencial (ver quadro 5).

Quadro 5: Categoria de Análise Normas e Regras

\begin{tabular}{|c|c|c|c|}
\hline & Origem & Descrição & $\begin{array}{c}\text { Modelo } \\
\text { predominante }\end{array}$ \\
\hline \multirow{3}{*}{$\begin{array}{c}\text { Normas } \\
\text { e regras }\end{array}$} & $\begin{array}{c}\text { Leis e Normas Federais; Planos, Programas } \\
\text { Federais e da MB; Normas e Orientações MB; }\end{array}$ & $\begin{array}{c}\text { Processo altamente } \\
\text { normatizado. }\end{array}$ & $\begin{array}{c}\text { Modelo } \\
\text { burocrático }\end{array}$ \\
\cline { 2 - 4 } & $\begin{array}{c}\text { Modelo de Melhoria de Processo de Software } \\
\text { Orasileiro (MPS.BR) }\end{array}$ & $\begin{array}{c}\text { Ferramenta que agrega } \\
\text { melhores práticas de gestão. }\end{array}$ & $\begin{array}{c}\text { Modelo } \\
\text { gerencial }\end{array}$ \\
\hline
\end{tabular}

Fonte: Elaborado pelos autores

Assim, percebe-se que com a interação com outros atores e organizações da administração federal, novas práticas são incorporadas aproximando-as daquelas preconizadas pelo modelo gerencial.

\section{f) Autonomia}

Considerou-se autonomia a faculdade de a organização em estudo se governar por si mesma, sendo percebida pela identificação de situações que envolvam a independência ou dependência em termos financeiros, materiais e tecnológicos.

As OMPS, dentre elas o CASNAV, face ao Contrato de Autonomia de Gestão assinado com a SGM, dispõem de maior flexibilidade na gestão de recursos, estipulando metas, resultados a alcançar e métodos de avaliação de desempenho. 
Práticas Estratégicas de Orçamentação e Faturamento na Administração Pública: Um Estudo de Caso na Marinha do Brasil

Quadro 6: Categoria de Análise Autonomia

\begin{tabular}{|c|c|c|c|}
\hline & Origem & Descrição & $\begin{array}{l}\text { Modelo } \\
\text { predominante }\end{array}$ \\
\hline \multirow{3}{*}{$\begin{array}{l}\text { Autonomi } \\
\text { a }\end{array}$} & $\begin{array}{l}\text { Baseada na } \\
\text { Lei de criação } \\
\text { da OMPS (Lei } \\
\text { no } 9.724 / 98)\end{array}$ & $\begin{array}{l}\text { Contrato de Autonomia de Gestão, flexibilidade na } \\
\text { gestão de recursos, estipulando metas, resultados a } \\
\text { alcançar e métodos de avaliação de desempenho. }\end{array}$ & \multirow[b]{2}{*}{ Modelo gerencial } \\
\hline & $\begin{array}{l}\text { Dos atores } \\
\text { sociais } \\
\text { ligados ao } \\
\text { processo }\end{array}$ & $\begin{array}{l}\text { Para realocação de recursos materiais e tecnológicos } \\
\text { em um determinado projeto; para alterar o cronograma } \\
\text { de recebimento de recursos de projetos; para realocação } \\
\text { de recursos entre projetos e compra de materiais; e para } \\
\text { definir práticas sob sua responsabilidade. }\end{array}$ & \\
\hline & $\begin{array}{l}\text { De origem } \\
\text { Hierárquica }\end{array}$ & $\begin{array}{l}\text { Atividades desenvolvidas pelos praticantes são } \\
\text { revisadas ou aprovadas pelo superior hierárquico. }\end{array}$ & $\begin{array}{l}\text { Modelo } \\
\text { burocrático e de } \\
\text { gestão militar. }\end{array}$ \\
\hline
\end{tabular}

Fonte: Elaborado pelos autores

Corroborando com essa flexibilidade, observase certa autonomia dos atores sociais ligados ao processo de orçamentação e faturamento para definir as práticas (ver quadro 6), assumindo a responsabilidade pelos documentos que eles assinam. Cada praticante assume a responsabilidade pelos seus atos, previamente definidos nas normas/regras, de acordo com seu posto/cargo. Entretanto, os relatos também evidenciam a necessidade da revisão ou aprovação das suas atividades pelo superior hierárquico, sugerindo que a autonomia é hierarquizada e muito centrada nos superiores, característica ainda de um modelo burocrático e do modelo de gestão militar.

\section{g) Recurso}

A categoria recurso é definida no presente estudo, em termos conceituais, como sendo condição viabilizadora das práticas (Mantere, 2008), podendo ter natureza impositiva e/ou alocativa e estando associado às noções de poder e coerção social (Jarzabkowski, 2008). Portanto, uma categorias que permite compreender como determinados instrumentos e mecanismos estão à disposição dos praticantes e os auxiliam (ou não) na adaptação das práticas na administração pública (Poister, 2010).

Os projetos desenvolvidos pelo CASNAV normalmente são de duração continuada. Os relatos indicam que os recursos recebidos guardam relação com a duração dos projetos e o escopo (execução física) a ser desenvolvido, sendo as exceções negociadas com os clientes.

$\mathrm{Na}$ outra ponta do processo, os pagamentos ao principal prestador de serviços do CASNAV também guardam relação com a execução dos serviços por ele prestados para os projetos.

Quadro 7: Categoria de Análise Recursos

\begin{tabular}{|c|c|c|c|}
\hline & Origem & Descrição & $\begin{array}{c}\text { Modelo } \\
\text { predominante }\end{array}$ \\
\hline \multirow{4}{*}{ Recursos } & Imposto pela União & $\begin{array}{l}\text { Descasamento entre a liberação do orçamentário e do } \\
\text { financeiro (contingenciamento). }\end{array}$ & \multirow{2}{*}{$\begin{array}{c}\text { Modelo } \\
\text { burocrático }\end{array}$} \\
\hline & $\begin{array}{l}\text { De Ator interno ou } \\
\text { solicitação cliente }\end{array}$ & Redefinição do escopo e recálculo; Termo Aditivo. & \\
\hline & $\begin{array}{l}\text { Gerados ou } \\
\text { utilizados pelos } \\
\text { praticantes internos }\end{array}$ & $\begin{array}{l}\text { Relatórios de acompanhamento a nível de indicador } \\
\text { físico e financeiro; cronograma de desembolso; } \\
\text { recurso disponível; trabalhei no vermelho; folga; e } \\
\text { folga de } 5 \% \text {. }\end{array}$ & \multirow[t]{2}{*}{$\begin{array}{l}\text { Modelo } \\
\text { gerencial }\end{array}$} \\
\hline & $\begin{array}{l}\text { Utilizados pelos } \\
\text { clientes }\end{array}$ & $\begin{array}{l}\text { Antecipação de pagamento de projetos, que possuem } \\
\text { acordos firmados entre as partes. }\end{array}$ & \\
\hline
\end{tabular}


Práticas Estratégicas de Orçamentação e Faturamento na Administração Pública: Um Estudo de Caso na Marinha do Brasil

Fonte: Elaborado pelos autores

Já os recursos financeiros destinados anualmente, e não utilizados, não podem ser transferidos para o ano seguinte. Ou eles são gastos pelo CASNAV ou são devolvidos aos clientes. De maneira geral, todos os entrevistados citaram que todos os recursos são gastos. Porém, essa limitação temporal afeta os projetos e o Plano de Metas de C, T\&I.

Dos relatos transcritos, pode-se destacar uma coerção existente, realizada pela própria União, que é "o descasamento entre a liberação do orçamentário e do financeiro". Esse é um recurso que está à disposição somente da União para exercer poder sobre as unidades, inclusive outras organizações militares. Por outro lado, vários recursos são utilizados para lidar com as restrições orçamentárias/financeiras, tanto pelos praticantes internos como pelos clientes, enquadrandose tanto dentro do modelo burocrático como do gerencial (quadro 7).

\section{h) Prática}

A categoria prática pode ser encontrada tanto de forma escrita como não escrita e retratam um hibridismo entre os modelos burocrático e gerencial. (ver quadro 8)

Quadro 8: Categoria de Análise Prática

\begin{tabular}{|c|c|c|c|}
\hline & Origem & Descrição & $\begin{array}{c}\text { Modelo } \\
\text { predominante }\end{array}$ \\
\hline \multirow{9}{*}{ Prática } & \multirow{3}{*}{ Regimento Interno } & Criação projetos temporários. & \multirow[t]{2}{*}{ Gerencial } \\
\hline & & Criação de grupos de conhecimento. & \\
\hline & & Formalização de atribuições. & Burocrático \\
\hline & $\begin{array}{l}\text { Excelência em } \\
\text { Gestão }\end{array}$ & $\begin{array}{l}\text { Cargo de gestão pela competência e não pelo } \\
\text { posto/hierarquia. }\end{array}$ & \multirow{3}{*}{ Gerencial } \\
\hline & \multirow{2}{*}{$\begin{array}{l}\text { Divisão de } \\
\text { relacionamento com } \\
\text { o cliente }\end{array}$} & $\begin{array}{l}\text { Criação de oportunidades de novos projetos e } \\
\text { estreitamento do relacionamento com os clientes. }\end{array}$ & \\
\hline & & $\begin{array}{l}\text { Proatividade de relacionamentos com a criação de } \\
\text { banco de dados de contatos. }\end{array}$ & \\
\hline & $\begin{array}{l}\text { Regulamento do } \\
\text { CASNAV }\end{array}$ & $\begin{array}{c}\text { Execução de projetos somente com aprovação do } \\
\text { Diretor, baseada na adequação às áreas de } \\
\text { competência técnica da OMPS. }\end{array}$ & Burocrático \\
\hline & Solicitação do cliente & $\begin{array}{l}\text { Lotação da equipe do projeto nas instalações do } \\
\text { cliente. }\end{array}$ & \multirow[t]{2}{*}{ Gerencial } \\
\hline & Praticante externo & Ator interno incorporando nova prática. & \\
\hline
\end{tabular}

Fonte: Elaborado pelos autores

Diante das restrições impostas pelos aspectos legais e orçamentários, a análise apontou que a prática de orçamentação e faturamento é viabilizada, simultaneamente: (i) pela formalização que é garantida pelas atribuições dos praticantes envolvidos no processo; (ii) pela proatividade e interação com os clientes, desenvolvida por intermédio da Divisão de Relacionamento com os Clientes; e (iii) pelas competências gerenciais (fora da hierarquia militar), conforme demonstrado na figura 2.

A partir dessas três grandes dimensões de prática que os praticantes lidam com as restrições impostas pela administração pública e, portanto, viabilizam o desenvolvimento das atividades em uma organização de projetos de inovação. 
Práticas Estratégicas de Orçamentação e Faturamento na Administração Pública: Um Estudo de Caso na Marinha do Brasil

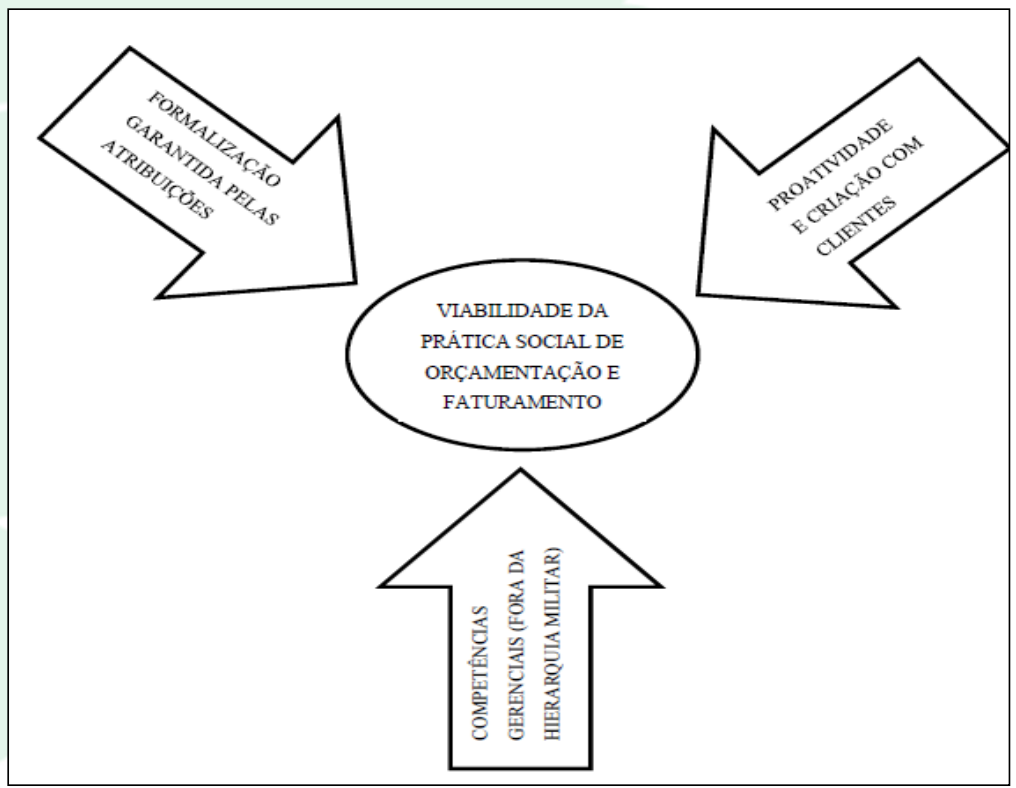

Figura 2: Elementos que viabilizam a prática de orçamentação e faturamento no CASNAV

Fonte: Elaborado pelos autores

\subsection{Formação das práticas sociais segundo modelo de Whittington}

Após análise das categorias, identificou-se que os clientes são os atores sociais da MB ou extra-MB que recebem os recursos orçamentários e financeiros e contratam o CASNAV para a execução de serviços.

Os recursos orçamentários e financeiros, recebidos pelos clientes, são oriundos do PPA e da LOA e são distribuídos na MB para os relatores de Plano Diretor, que os alocam às Metas a serem anualmente executadas.

Dentre os principais resultados da análise destaca-se, portanto, que a formação de práticas está diretamente ligada aos clientes, visto que a ausência deles faz com que o processo de orçamentação e faturamento não ocorra efetivamente. Além disso, a pesquisa evidenciou que a flexibilidade para lidar com as restrições orçamentárias ou financeiras está muito relacionada às necessidades do cliente, ou seja, as demandas dele são aceitas internamente e as práticas são ajustadas para dar conta de suas solicitações. Da mesma forma, destaca-se que, sempre no intuito de gerir eficazmente os recursos públicos, os processos são otimizados e/ou os recursos são realocados entre ações internas do Plano de Metas ou entre projetos.

O modelo de Whittington (2006) indica a influência de atores externos na adoção de práticas estratégicas nas organizações e que as práticas estratégicas são utilizadas pelos praticantes em suas práxis. Com base nesses conceitos, a análise aponta que práticas de orçamentação e faturamento são impactadas pelas restrições/regras orçamentárias e financeiras e os praticantes adaptam suas práxis às realidades/necessidades dos clientes, que por sua vez, adequam seus projetos aos recursos recebidos de forma a lidar com as mesmas.

Assim, coexistem os atributos de recursividade e adaptação que buscam atender às necessidades de estabilidade e mudança com que se deparam os estrategistas. As necessidades de estabilidade são atendidas pelas regras e regulamentos previstos no aparato normatizador e burocrático da organização. Por outo lado, os praticantes internos fazem adaptações, que resultam da interação do macro contexto (sociedade) com o micro contexto (organização). Essas adaptações se tornam possíveis graças a flexibilidade, autonomia e recursos introduzidos na administração da organização pelo modelo gerencia. (Jarzabkowski, 2004).

A partir dos resultados apresentados nesta seção, parte-se na próxima seção para a elaboração de considerações finais quanto ao alcance dos objetivos e à resposta à pergunta de pesquisa por meio da pesquisa empreendida.

\section{CONSIDERAÇÕES FINAIS}

O presente estudo procurou compreender como os praticantes formam práticas estratégicas no processo de orçamentação e faturamento no CASNAV, de forma a cumprir a missão da organização (desenvolver projetos de inovação tecnológica) e a atender às 
Práticas Estratégicas de Orçamentação e Faturamento na Administração Pública: Um Estudo de Caso na Marinha do Brasil

demandas da sociedade, em um contexto de hibridismo entre os modelos burocrático e gerencial.

A análise das práticas envolvidas no processo de orçamentação indica a possível existência da aproximação de um perfil gerencial, uma vez que as decisões são tomadas com o suporte do referido processo. Pelos relatos, há indícios de que ele acontece e se desenrola em função de elementos que são negociados, acertados e estudados e, somente após, as aprovações são formalizadas para documentar o previamente acordado.

A existência de uma Divisão de Relacionamento com o Cliente, a utilização do modelo MPS.BR e do sistema de qualidade são exemplos de práticas estratégicas que contribuem para que a organização seja reconhecida como referência nas áreas de sua atuação.

Os projetos desenvolvidos pelo CASNAV normalmente são de duração continuada e seu acompanhamento físico e financeiro é efetuado periodicamente por meio de indicadores de desempenho. Estes indicadores apontam as eventuais necessidades de adequação de recursos (humanos, financeiros ou de material) e os gestores do nível tático as compartilham com o nível estratégico em reuniões específicas na organização. Em seguida, negociam com os clientes as adaptações necessárias à conclusão dos projetos quanto ao prazo, preço ou escopo, evidenciando práticas do modelo gerencial.

As restrições financeiras afetam negativamente os investimentos em atualização tecnológica da organização, impactando diretamente no desenvolvimento de novos projetos de desenvolvimento de sistemas. Porém, eles são minimizados com a interação com atores de outras organizações, a exemplo das parcerias com instituições de fomento ao desenvolvimento e inovação tecnológicos.

A prestação de serviço de apoio técnico na área de desenvolvimento contratada pela organização pela modalidade de dispensa de licitação pode ser considerado um recurso que flexibiliza e viabiliza a execução dos projetos desenvolvidos pelo CASNAV.

Resumidamente, as práticas da organização aparentemente se aproximam mais daquelas desenvolvidas por empresas privadas como IBM ou SAP, do que daquelas desenvolvidas por uma organização pública. Assim, as práticas estratégicas formadas aproximam-se do perfil gerencial, propiciando à organização potencial para tornar-se fornecedora para vários outros clientes ou tipos de serviços, mesmo se tratando de uma organização militar e pública. Ou seja, a aproximação com o modelo gerencial parece garantir a flexibilidade necessária às organizações que atuam na área de inovação e tecnologia, apesar da presença de traços do modelo burocrático em suas práticas estratégicas.

As considerações acima expostas mostraram-se importantes para destacarmos a relevância da pesquisa que se propôs a estudar as práticas de orçamentação e faturamento formadas cotidianamente em uma organização militar prestadora de serviços, de forma a lidar com as restrições/regras da Administração Pública. Em termos práticos, considera-se que a presente pesquisa seja relevante, não apenas para os gestores de OMPS da MB, mas também para gestores públicos e formuladores de políticas públicas que atuam em organizações ligadas a outros Ministérios e entes federativos. Em termos teóricos, considera-se que a presente pesquisa seja relevante por utilizar a abordagem de prática social em estudos em contabilidade e gestão pública, por meio do modelo de Whittington (2006), como forma de revelar que os gestores públicos adaptam cotidianamente suas ações, balizados por regras e normas recursivamente aplicadas, como forma de lidar com a coexistência dos modelos burocrático e gerencial na administração pública brasileira.

Entretanto, cabe destacar que os resultados aqui apresentados mostram-se limitados devido ao reconhecimento de que a presente pesquisa, apesar de sua orientação longitudinal, foi empreendida de forma seccional. Portanto, a formação das práticas aqui analisada mostra-se limitada ao contexto espaçotemporal em que a coleta de dados foi empreendida, considerando-se o reconhecimento de que as mesmas são socialmente construídas e transformam-se com o tempo.

Por fim, sugere-se como pesquisas futuras: ampliar a pesquisa para outras organizações militares prestadoras de serviço a fim de comparar os resultados obtidos e verificar se o hibridismo dos modelos burocrático e gerencial está presente em outras organizações militares e sua implicação nas organizações a serem estudadas. Sugere-se também a realização de pesquisas focadas em outras organizações públicas da área de ciência, tecnologia e inovação, de forma a apontar as proximidades e afastamentos dos resultados obtidos com o presente estudo de caso. 
Práticas Estratégicas de Orçamentação e Faturamento na Administração Pública: Um Estudo de Caso na Marinha do Brasil

\section{REFERÊNCIAS}

Andion, Carolina. (2012). Por uma Nova Interpretação das Mudanças de Paradigma na Administração Pública. Cad.EBAPE.BR, 10(1): 1-19.

Andrews, C. W., \& Bariani, E. (Orgs.). (2010). Administração pública no Brasil: breve história politica. SP: Unifesp.

Bardin, Laurence. (1977). Análise de Conteúdo. Tradução Luís Antero Reto e Augusto Pinheiro. Lisboa: Edições 70.

Barzelay, Michael. (1993). The Single Case Study as Intellectually Ambitious Inquiry. Journal of Public Administration Research and Theory: J-PART, 3(3): 305-318.

Baxter, J., \& Chua, W. F. (2003). Alternative management accounting research — whence and whither. Accounting. Organizations and Society, 28: 97-126.

Brasil. (1988). Constituição da República Federativa do Brasil de 1988. Diário Oficial [da] República Federativa do Brasil. Brasília, DF.

(2010). Lei Complementar $n^{\circ} 136$, de 25 de agosto de 2010. Altera a Lei Complementar $n^{\circ} 97$, de 9 de junho de 1999, que "dispõe sobre as normas gerais para a organização, o preparo e o emprego das Forças Armadas", para criar o EMCFA e disciplinar as atribuições do Ministro de Estado da Defesa. Brasil. Brasília, DF.

Bresser-Pereira, Luiz Carlos. (2000). A reforma gerencial do Estado de 1995. Revista de Administração Pública, 34(4): 7-26, jul./ago.

Bryson, J. M., Berry, F. S., \& Yang, K. (2010). The State of Public Strategic Management Research: A Selective Literature Review and Set of Future Directions. The American Review of Public Administration, 40(5): 495-521.

Cardoso Jr., J. C. (2015). Política e Planejamento no Brasil: Balanço Histórico e Propostas ao Plano Plurianual 2020-2023. IN: Cardoso Jr., J. C. (org.) Planejamento Brasil século XXI: inovação institucional e refundação administrativa. Cap. 4, pp. 135-170.

Centro de Análises de Sistemas Navais. (2012). Regulamento do CASNAV. Rio de Janeiro.
Rio de Janeiro.

(2012a). Regimento Interno do CASNAV.

Cavalcante, P. L. C. (2012). Avaliação dos Programas do PPA: estudo de caso da implantação do orçamento por desempenho. Revista Gestão $e$ Planejamento, 13(3): 232-246.

Centro de Análises de Sistemas Navais. (2012b). Relatório de Gestão do CASNAV. Rio de Janeiro: Marinha do Brasil.

Clegg, S., Courparsson, D., \& Phillips, N. (2006). Power and Organizations. Londres: Sage.

Cuganesan, S., Dunford, R., \& Palmer, I. (2012). Strategic management accounting and strategy practices within a public sector agency. Management Accounting Research, 23(4): 245-260.

Drumond, A. M., Silveira, S. F. R., \& Silva, E. A. (2014). Predominância ou coexistência? Modelos de administração pública brasileira na Política Nacional de Habitação. Rev. Adm. Pública, 48(1): 3-25.

Ferlie, E. (2002). Quasi Strategy: Strategic Management in the Contemporary Public Sector. In: Pettigrew, A. Thomas, H Whittington, R. Handbook of Strategy and Management. London: Sage, cap. 14.

Guarido Filho, E. R., \& Costa, M. C. (2012). Contabilidade e Institucionalismo Organizacional: Fundamentos e Implicações para Pesquisa. Rev. Cont. Controladoria, 4(1).

Guerreiro Ramos, A. (1981). A Nova ciência das organizações: uma reconceituação da riqueza das nações. Rio de Janeiro: FGV.

Guerreiro, R., Frezatti, F., \& Casado, T. (2006). Em busca de um melhor entendimento da contabilidade gerencial através da integração de conceitos da psicologia, cultura organizacional e teoria institucional. R.Cont.Fin. USP, São Paulo. p.7-21, set.

Hood, C. (2005). Public Management: the world, the movement, the science. In: Ferlie, E., Lynn Jr., \& L. E.; Pollitt, C. Oxford Handbook of Public Management, cap. 1, pp. 7-26.

Jarzabkowski, P. (2008). Shaping Strategy as a Structuration Process. Academy of Management Journal, 51(4): 621-650. 
Práticas Estratégicas de Orçamentação e Faturamento na Administração Pública: Um Estudo de Caso na Marinha do Brasil

Jarzabkowski, P. (2004). Strategy as Practice: Recursiveness, Adaptation, and Practices-in-Use. Organization Studies, 25(4): 529-560.

Lounsburry, M. (2008). Institutional rationality and practice variation: New directions in the institutional analysis of practice. Accounting, Organizations and Society, 33(4-5): 349-361.

Lynn, L. E. (2005). Public Management: a concise history of the Field. In: Ferlie, E., Lynn Jr., L. E., \&Pollitt, C. Oxford Handbook of Public Management, cap. 2.

Mantere, S. (2008). Role expectations and middle manager strategic agency. Journal of Management Studies, 45(2): 294-316, mar.

Marinha do Brasil. (2008). Secretaria Geral da Marinha. SGM-304 - Normas sobre Contabilidade das Organizações Militares Prestadoras de Serviços (OMPS). Brasília, DF

Ministério da Administração Federal e da Reforma do Estado. (1995). Plano Diretor da Reforma do Aparelho do Estado, Brasília, 1995.

Ministério do Planejamento, Orçamento e Gestão. (2011). Secretaria de Planejamento e Investimentos Estratégicos. Plano plurianual 2012-2015: projeto de lei, Brasília: MP, 278 p.

Mintzberg, Henry. (1996). Managing Government, Governing Management. Harvard Business Review: 75-83, maio/jun.

Moreira, H., \& Caleffe, L. G. (2008). Metodologia da pesquisa para o professor pesquisador. 2.ed. Rio de Janeiro: Lamparina.

Poister, T. H. (2010). The Future of Strategic Planning in the Public Sector: Linking Strategic Management and Performance. Public Administration Review, Special Issue: 246-254.

Prestes Motta, F.C., \& Vasconcelos, I. F. G. (2004). Teoria Geral da Administração. São Paulo: Pioneira Thomson Learning.

Ryan, B., Scapens, R. W., \& Theobald, M. (2002). Research Method and Methodology in Finance and Accounting. London: Wouth Wester: Cengage Learning.

Santos, M. F. B., Fonseca, A. C. P. D., \& Sauerbronn, F. F. (2014). Cultura Organizacional e Avanço do Management na Marinha do Brasil. Cad. EBAPE.BR, 12(1): 131-162.
Motta, F. L. (2001). Contabilidade aplicada à administração pública. 5.ed.Brasília: Vestcon.

Motta, P. R. M. (2013). O Estado da Arte da Gestão Pública. Revista de Administração de Empresas, 53(1): 82-90.

Rocha Neto, L. H. (2008). A formação do Estado brasileiro: Patrimonialismo, Burocracia e Corrupção. Revista do Mestrado em Direito UCB, 2 (1): 204-230.

Marinha do Brasil. (2013). SGM-401 - Normas para Gestão do Sistema do Plano Diretor. Brasília, DF.

Matias-Pereira, J., \& Kruglianskas, I. (2005). Gestão de inovação: a Lei de Inovação Tecnológica como ferramenta de apoio às políticas industrial e tecnológica do Brasil. RAE-eletrônica, 4(2), jul./dez.

Medeiros, Paulo Henrique Ramos. (2006). Do modelo racional-legal ao paradigma pós-burocrático: reflexões sobre burocracia estatal. Organizações \& Sociedade, 13(37): 143-160.

Nascimento, Edson R. (2010). Gestão pública. 2. ed. São Paulo: Saraiva.

Paula, Ana Paula Paes de. (2005). Administração Pública Brasileira entre o Gerencialismo e a Gestão Social. Revista de Administração de Empresas, 45(1): 36-49.

Pinho, José Antonio Gomes. (1998). Reforma do Aparelho do Estado: Limites do Gerencialismo frente ao Patrimonialismo. Organizações \& Sociedade (O\&S), 5(12): 59-79.

Secchi, Leonardo. (2009). Modelos organizacionais e reformas da administração pública. Revista de Administração Pública, Rio de Janeiro, 43(2): 347-369.

Smith, M. (2011). Research methods in accounting. London: SAGE Publications.

Stake, R. E. (2005). Case Studies. In: Denzin, N., \& Lincoln, Y. Handbook of Qualitative Research: Strategies of qualitative inquiry, Londres: Sage, Chapter 4, p. 86-109. 
Práticas Estratégicas de Orçamentação e Faturamento na Administração Pública: Um Estudo de Caso na Marinha do Brasil

Valadares, J. L., \& Emmendoerfer, M. L. (2012). Cargos de Livre Nomeação: Reflexões com Base no Empreendedor Público em um Estado-Membro do Brasil. Revista de Administração Contemporânea, 16(5): 723-743.

Vieira, M. M. F. (2007). Por uma Boa Pesquisa (Qualitativa) em Administração. In: Vieira, M. M. F., \& Zouain, D. M. (Orgs.). Pesquisa qualitativa em administração. 2. ed. Rio de Janeiro: FGV, Capítulo 1: pp.13-28.

Walter, S. A., \& Augusto, P. O. M. (2011). O caleidoscópio da estratégia. O papel das consultorias externas no strategizing de uma organização. Revista Portuguesa e Brasileira de Gestão, jan/jun, p. 102-111.
Walter, S. A., Augusto, P. O. M., \& Fonseca, V. S. (2011). O Campo Organizacional e a Adoção de Práticas Estratégicas: Revisitando o Modelo de Whittington. Cadernos EBAPE.BR, 9(2): 282-298.

Whittington, R. (2004). Strategy after modernism: recovering practice. European Management Review, $1(1), 62-68$.

Whittington, R. (2006). Completing the Practice Turn in Strategy Research. Organization Studies, London, 27(5): 613-634. 